\title{
Determination of Metals and Metalloids in Wine Using Inductively Coupled Plasma Optical Emission Spectrometry and Mini-torch
}

\author{
Anetta Ziola-Frankowska $^{1}$ - Marcin Frankowski ${ }^{2}$ \\ Received: 18 February 2016 / Accepted: 1 June 2016 / Published online: 15 June 2016 \\ (C) The Author(s) 2016. This article is published with open access at Springerlink.com
}

\begin{abstract}
In the present study, an inductively coupled plasma optical emission spectrometer ICPE-9820 with the mini-torch technology that significantly reduces the consumption of plasma gas to $7.0 \mathrm{~L} \mathrm{~min}^{-1}$ was applied for the multielemental analysis of wine samples. Three sample preparation procedures (microwave digestion in closed vessels, acid digestion in open vessels in a water bath, both with $\mathrm{HNO}_{3}$, and 1:10 dilution with deionized water) were compared for the determination of 15 elements in wines. In all wines analyzed, the lowest concentration was obtained for $\mathrm{Li}\left(0.06-0.09 \mathrm{mg} \mathrm{L}^{-1}\right)$ and the highest for $\mathrm{K}$ (475$995 \mathrm{mg} \mathrm{L}^{-1}$ ). The concentration $>1 \mathrm{mg} \mathrm{L}^{-1}$ of $\mathrm{B}, \mathrm{Fe}$, and $\mathrm{Na}$ was determined in all wines analyzed by the three sample preparation procedures. The average concentrations found for the acid extracts for $\mathrm{Al}\left(1.31 \mathrm{mg} \mathrm{L}^{-1}\right)$ and $\mathrm{Fe}\left(3.40 \mathrm{mg} \mathrm{L}^{-1}\right)$ were higher in comparison to results of sample dilution $\left(0.73\right.$ and $1.56 \mathrm{mg} \mathrm{L}^{-1}$ respectively). The recoveries were between 88.2 and $110 \%, 65.9$ and $106 \%$, and 62.8 and $109 \%$, whereas the relative standard deviations (RSDs) varied between 0.04 and $4.62 \%, 0.74$ and $5.57 \%$, and 0.70 and $5.80 \%$, respectively, for the procedure of sample dilution, microwave digestion, and water bath digestion.
\end{abstract}

Electronic supplementary material The online version of this article (doi:10.1007/s12161-016-0567-6) contains supplementary material, which is available to authorized users.

Anetta Zioła-Frankowska

anettazf@amu.edu.pl

1 Faculty of Chemistry, Department of Analytical Chemistry, Adam Mickiewicz University in Poznań, Umultowska 89b, 61-614 Poznan, Poland

2 Faculty of Chemistry, Department of Water and Soil Analysis, Adam Mickiewicz University in Poznań, Umultowska 89b, 61-614 Poznan, Poland
Keywords Wine - Inductively coupled plasma (ICP) · Optical emission spectrometry (OES) - Low gas flow • Multielement analysis - Food analysis - Food composition

\section{Introduction}

It is well known that the application of inductively coupled plasma optical emission spectrometry (ICP OES) showed powerful analytical performance (Thiel and Danzer 1997; Yabuta et al. 2002; Nowak et al. 2014, 2015; Luis et al. 2015). The ICP OES technique has been extensively employed in the determination of trace elements in wine (Péres-Jordán et al. 1998; Gonzálvez et al. 2008; Rodrigues et al. 2011; Alkiş et al. 2014). Despite many advantages of this technique, one of the main problems is the high consumption of plasma-forming gas. An average consumption of argon when using a typical torch during the analysis is from 15 to $25 \mathrm{~L} \mathrm{~min}^{-1}$ (Yabuta et al. 2002; Larrera-Marín et al. 2010; Nunes et al. 2013; Szymczycha-Madeja and Welna 2013; Santos et al. 2014). In order to reduce the use of argon, different approaches can be applied: miniaturization of the torch or modification of the way of cooling the entire system (air or water) (Yabuta et al. 2002; Nowak et al. 2014).

For the determination of elemental composition of wines, it is required to properly prepare the samples. Taking into consideration that wine is a complex water-ethanol mixture, containing various inorganic and organic substances at different levels (Álvarez et al. 2007; Pyrzyńska 2007; Gonzálvez et al. 2008; Moreno et al. 2008; Voica et al. 2009; Rodrigues et al. 2011), the sample preparation stage is very important in the analysis of particular wine components. The preparation of wine samples for metal and metalloid determination includes microwave-assisted acid digestion, UV-assisted digestion, thermal digestion in an open reactor, sample dilution, dry 
and wet ashing, and also less common approaches such as dealcoholization or analyte separation (Gonzálvez et al. 2008; Ivanowa-Petropulos et al. 2015). Moreover, when choosing the method of wine sample preparation, it should be considered which procedure provides the best results in the shortest time, with minimum losses and contamination risk, consumes the smallest quantities of reagents and samples, and generates little amounts of residues and wastes (Gonzálvez et al. 2008).

The aim of this study was to find optimal working conditions for an ICP OES spectrometer which would allow us to perform the multielemental analysis of wine samples with the least possible consumption of argon (plasma gas). Additionally, a comparative study of red and white wine sample preparation procedures was conducted for the determination of Al, B, Ba, Cu, Fe, Li, Mn, Se, Sr, Zn, Ca, Mg, Na, P, and K by ICP OES. Furthermore, the accuracy of the selected sample pretreatments was evaluated by the comparison of the ICP OES results obtained for wine samples after having been treated by either digestion procedures or simple sample dilution.

\section{Materials and Methods}

\section{Reagents}

Sigma Aldrich (USA) stock solution containing Al, B, Ba, Cu, $\mathrm{Fe}, \mathrm{Li}, \mathrm{Mn}, \mathrm{Se}, \mathrm{Sr}, \mathrm{Zn}, \mathrm{Ca}, \mathrm{Mg}, \mathrm{Na}, \mathrm{P}$, and K (1000 mg L ${ }^{-1}$ for each element) were used to prepare calibration standards. The calibration range for $\mathrm{Al}, \mathrm{B}, \mathrm{Ba}, \mathrm{Cu}, \mathrm{Fe}, \mathrm{Li}, \mathrm{Mn}, \mathrm{Se}, \mathrm{Sr}$, and $\mathrm{Zn}$ was $10-1000 \mu \mathrm{g} \mathrm{L}^{-1}$, and for the highly concentrated elements such as $\mathrm{Ca}, \mathrm{Mg}, \mathrm{Na}, \mathrm{P}$, and $\mathrm{K}$, it was 100-10, $000 \mu \mathrm{g} \mathrm{L}^{-1}$. The suprapure $69 \% \mathrm{HNO}_{3}(\mathrm{~m} / \mathrm{m})$ from Sigma Aldrich (USA) and deionized water with the maximum resistivity of $18.2 \mathrm{M} \Omega \mathrm{cm}^{-1}$ obtained from the Hydrolab System (Gdansk, Poland) were used for sample (pre)treatment and sample dilution.

\section{Instrumentation}

A Shimadzu ICPE-9820 spectrometer (Shimadzu, Japan) was used for the analysis of wine samples. This spectrometer with the vertical orientation of mini-torch works both with axial (for low concentration of elements) and radial (for high concentration of elements) plasma observation within one sequence. Moreover, the orientation of the torch reduces memory effect and ensures stable results of analysis even for samples with high concentrations of acids, salts, or for a variety of organic solvents. Also, this spectrometer can work with the argon gas of $99.95 \%$ purity instead of the normally used $99.999 \%$. The samples were introduced into the plasma using a high-accuracy nebulizer by free aspiration and a gravity drain. Emission lines were selected based on their sensitivity. The ionic lines of Ba II (455.403 nm), Ca II (393.366 nm), Fe II (259.940 nm), Mg II (279.553 nm), Mn II (257.610 nm), Sr II $(407.771 \mathrm{~nm})$, and atomic lines of Al I (394.403 nm), B I (249.773 nm), Cu I (327.396 nm), K I (766.490 nm), Li I (610.364 nm), Na I (589.592 nm), P I (178.287 nm), Se I $(196.090 \mathrm{~nm})$, and $\mathrm{Zn} \mathrm{I}(213.856 \mathrm{~nm})$ were measured. Table 1 presents the operating conditions and accessories for the multielemental analysis of wines on an ICP OES spectrometer (Shimadzu ICPE-9820, Japan). The limit of detection (LOD) values were calculated as the concentrations corresponding to signals equal to three times the standard deviation of blank solution signal, both for 10 and $7.0 \mathrm{~L} \mathrm{~min}^{-1}$ plasma flow rate.

\section{Microwave}

Microwave sample digestion was carried out with CEM Mars 5 (CEM Corporation, Mathews, NC, USA) instrument. The samples were digested using the program recommended by the manufacturer (16 vessels). Table 2 presents operational parameters for microwave digestion.

\section{Samples}

Four samples of wines, including one sample of white wine (Resling) and three samples of red wine (Roja, Bordeux, and Carlo Rossi), were analyzed. Wine bottles were purchased in Polish supermarkets. The alcoholic content ranged from 12.0 to $13.5 \% v / v$ ethanol. All the wine samples were from 2012 to 2014 vintages. The containers used for storage or treatment of the samples were cleaned to avoid contamination with any metals. The containers were treated with nitric acid and washed with deionized water. Wine samples were handled according to three preparation procedures, immediately after opening the bottles.

\section{Procedures of Sample Preparation}

Wine samples for determination of metals and metalloids content were pretreated using the three different procedures described below. Each sample of wine was prepared in triplicate for each method. Blanks were prepared in an identical way as the samples.

\section{Dilution}

Samples of wines were diluted 10 times with deionized water, without any prior preparation. 
Table 1 Operating conditions and accessories employed in ICP OES spectrometer (Shimadzu ICPE-9820) for the analysis of wine samples

\begin{tabular}{|c|c|c|c|c|c|c|c|c|c|c|c|c|c|c|c|}
\hline \multicolumn{9}{|c|}{ Parameter and accessories } & \multicolumn{7}{|l|}{ Value } \\
\hline \multicolumn{9}{|c|}{ Radio frequency power generator } & \multicolumn{7}{|c|}{$1.2 \mathrm{~kW}$} \\
\hline \multicolumn{9}{|c|}{ Gas type } & \multicolumn{7}{|c|}{ Argon } \\
\hline \multicolumn{9}{|c|}{ Plasma gas flow rate } & \multicolumn{7}{|c|}{$7.0 \mathrm{~L} \mathrm{~min}^{-1}$} \\
\hline \multicolumn{9}{|c|}{ Auxiliary gas flow rate } & \multicolumn{7}{|c|}{$0.6 \mathrm{~L} \mathrm{~min}^{-1}$} \\
\hline \multicolumn{9}{|c|}{ Nebulization gas flow rate } & \multicolumn{7}{|c|}{$0.7 \mathrm{~L} \mathrm{~min}^{-1}$} \\
\hline \multicolumn{9}{|l|}{ Plasma view } & \multicolumn{7}{|c|}{ Vertical torch; axial/radial view } \\
\hline \multicolumn{9}{|l|}{ Torch } & \multicolumn{7}{|c|}{ Mini-torch (quartz) } \\
\hline \multicolumn{9}{|l|}{ Nebulizer } & \multicolumn{7}{|c|}{ Burgener NX-175 } \\
\hline \multicolumn{9}{|l|}{ Chamber } & \multicolumn{7}{|c|}{ Cyclone (glass) } \\
\hline \multicolumn{9}{|l|}{ Drain } & \multicolumn{7}{|c|}{ Gravity fed } \\
\hline \multicolumn{9}{|l|}{ Injector tube } & \multicolumn{7}{|c|}{ Quartz (1.2 mm i.d.) } \\
\hline \multicolumn{9}{|c|}{ Background correction } & \multicolumn{7}{|c|}{2 points } \\
\hline \multicolumn{9}{|c|}{ Number of replicates } & 3 & & & & & & \\
\hline Exposure time & & & & & & & & & $15 \mathrm{~s}$ & & & & & & \\
\hline Peristaltic pump & & & & Solver & inse & & & & $10 \mathrm{~s}$ & & & & & & \\
\hline & & & & Sampl & inse & & & & $5 \mathrm{~s}$ & & & & & & \\
\hline & & & & Sampl & uptake $\mathrm{r}$ & & & & $1 \mathrm{~mL} \mathrm{n}$ & $\mathrm{in}^{-1}$ & & & & & \\
\hline Spectrometer & & & & Echell & ptics & & & & Range & f wavel & th 167 & $800 \mathrm{n}$ & & & \\
\hline & & & & Resolt & & & & & $\leq 0.005$ & $\mathrm{~m}$ at 20 & & & & & \\
\hline & & & & Atmos & eric ren & val syst & & & Rotary & acuum & $\mathrm{mp} \leq 10$ & & & & \\
\hline Device & & & & $\mathrm{CCD}$ & arge co & led dev & detec & & & & & & & & \\
\hline & & & & Pixel 1 & nber & & & & $1024 \times$ & 1024 pi & s $(1-$ in. $)$ & & & & \\
\hline & & & & Pixel s & & & & & $20 \mu \mathrm{m}$ & $20 \mu \mathrm{m}$ & & & & & \\
\hline & & & & Coolin & control & & & & Peltier & evice & & & & & \\
\hline $\operatorname{LOD}\left[\mu \mathrm{g} \mathrm{L}^{-1}\right]$ & $\mathrm{Al}$ & B & $\mathrm{Ba}$ & $\mathrm{Ca}$ & $\mathrm{Cu}$ & $\mathrm{Fe}$ & $\mathrm{K}$ & $\mathrm{Li}$ & $\mathrm{Mg}$ & $\mathrm{Mn}$ & $\mathrm{Na}$ & $\mathrm{P}$ & $\mathrm{Se}$ & $\mathrm{Sr}$ & $\mathrm{Zn}$ \\
\hline $7.0 \mathrm{~L} \mathrm{~min}^{-1}$ & 1.273 & 0.201 & 0.321 & 0.333 & 0.758 & 0.211 & 2.06 & 0.039 & 0.07 & 0.239 & 0.502 & 4.21 & 4.75 & 0.923 & 0.171 \\
\hline $10.0 \mathrm{~L} \mathrm{~min}^{-1}$ & 1.113 & 0.388 & 0.399 & 0.375 & 0.913 & 0.328 & 1.66 & 0.037 & 0.042 & 0.364 & 0.642 & 6.65 & 7.25 & 0.701 & 0.577 \\
\hline
\end{tabular}

\section{Microwave-Assisted Digestion}

Digestion of wine samples was carried out in the PTFE (polytetrafluoroethylene) vessels (which were previously cleaned in concentrated nitric acid to avoid any contamination) accompanying the microwave oven used. Each time, $2 \mathrm{~mL}$ of wine sample and $8 \mathrm{~mL}$ of $\mathrm{HNO}_{3}$ were transferred to the vessel. The acid was added in portions, as the addition of the entire amount at once would cause a loss of the analyte due to excessively rapid reaction of organic matter in wine and heating. After the digestion step had been completed, the digestion vessels were cooled to room temperature. Then, the resultant solutions were transferred to glass flasks and diluted with deionized water to the final volume of $25 \mathrm{~mL}$.

\section{Water Bath-Assisted Digestion}

Acid digestion of wine samples was carried out in a water bath, in conical flasks with Vigroux-type columns. Each time,
$2 \mathrm{~mL}$ of wine sample was transferred to the flask, followed by slow addition of $8 \mathrm{~mL}$ of concentrated suprapure nitric acid. Then, the flasks were heated in a water bath at $95^{\circ} \mathrm{C}$ for $1 \mathrm{~h}$. After the flasks had cooled to room temperature, the resultant solutions were transferred to glass flasks and diluted with deionized water to the final volume of $25 \mathrm{~mL}$.

\section{Results and Discussion}

\section{Influence of Plasma and Carrier Gas Flows on the ICP OES Measurements}

The new features of the spectrometer employed allows to multielemental analysis using less argon. In the application note (No. SCA-115-023, www.schimadzu.eu) concerning the determination of selected elements in wines, available from Shimadzu, the use of mini-torch allows a plasma gas flow rate of $10 \mathrm{~L} \mathrm{~min}{ }^{-1}$. In the
Table 2 Microwave oven program applied for wine samples digestion

\begin{tabular}{llllll}
\hline Step & $\begin{array}{l}\text { Initial temperature } \\
\left({ }^{\circ} \mathrm{C}\right)\end{array}$ & $\begin{array}{l}\text { Final temperature } \\
\left({ }^{\circ} \mathrm{C}\right)\end{array}$ & $\begin{array}{l}\text { Ramp time } \\
(\mathrm{min})\end{array}$ & $\begin{array}{l}\text { Hold time } \\
(\mathrm{min})\end{array}$ & $\begin{array}{l}\text { Power } \\
(\mathrm{W})\end{array}$ \\
\hline 1 & 25 & 175 & 5.30 & 4.30 & $1600(80 \%)$ \\
$2^{*}$ & 175 & 25 & 5.00 & 0 & 0 \\
\hline
\end{tabular}

* Cool down step 
present study, the plasma gas flow rate was optimized in order to further reduce the consumption of argon in the analysis. The first step was to examine to what extent the consumption of argon would affect the accuracy. To this end, solutions with known analyte concentration (Al, B, $\mathrm{Ba}, \mathrm{Cu}, \mathrm{Fe}, \mathrm{Li}, \mathrm{Mn}, \mathrm{Se}, \mathrm{Sr}, \mathrm{Zn}-1 \mathrm{mg} \mathrm{L}^{-1}$, and for $\mathrm{Ca}$, $\mathrm{Mg}, \mathrm{Na}, \mathrm{P}$ and $\mathrm{K}-10 \mathrm{mg} \mathrm{L}^{-1}$ ) were analyzed. Based on the results, it was observed that the best recoveries were obtained for the argon flow rates of 10 and $7.0 \mathrm{~L} \mathrm{~min}^{-1}$ (Fig. 1). The greatest differences in the levels of concentrations were reported for macronutrients $(\mathrm{Ca}, \mathrm{K}, \mathrm{Mg}, \mathrm{Na}$, and P). Nonetheless, the conducted argon flow rate optimization enabled to reduce the flow rate to $7.0 \mathrm{~L} \mathrm{~min}^{-1}$ while maintaining high precision, as shown in Fig. 1.

The impact of different carrier (nebulizer) gas flow rates $\left(0.8,0.7,0.6\right.$, and $\left.0.5 \mathrm{~L} \mathrm{~min}^{-1}\right)$ on the analyte concentrations was also studied at the plasma gas flow rate of $7.0 \mathrm{~L} \mathrm{~min}^{-1}$. It was observed that the best results were obtained for $0.7 \mathrm{~L} \mathrm{~min}^{-1}$ (Fig. 2). The other examined flow rates significantly under- or overestimated the actual metal concentrations in standard solutions.

\section{Effect of Sample Pretreatment in ICP OES Determinations}

The wine samples were prepared following three different procedures: simple dilution with water, digestion assisted by microwave, or heating on water bath. In the prepared samples, 15 elements were determined by ICP OES. The obtained concentrations ranged widely from $1.0 \mathrm{mg} \mathrm{L}^{-1}<$ to $1000 \mathrm{mg} \mathrm{L}^{-1}$, depending on the type of wine. In all wine samples, the highest concentrations were determined for potassium and the lowest for lithium.

\section{Sample Dilution}

Taking into consideration that sample dilution can mitigate wine matrix effect by simultaneous reduction of inorganic and organic compound-related interferences, this method seems to be a fast and precise way of sample preparation (Gonzálvez et al. 2008). In the present study, the dilution of $1: 10(v / v)$ was used; it was sufficient for the elimination of matrix effects, especially the amount of salts and organic
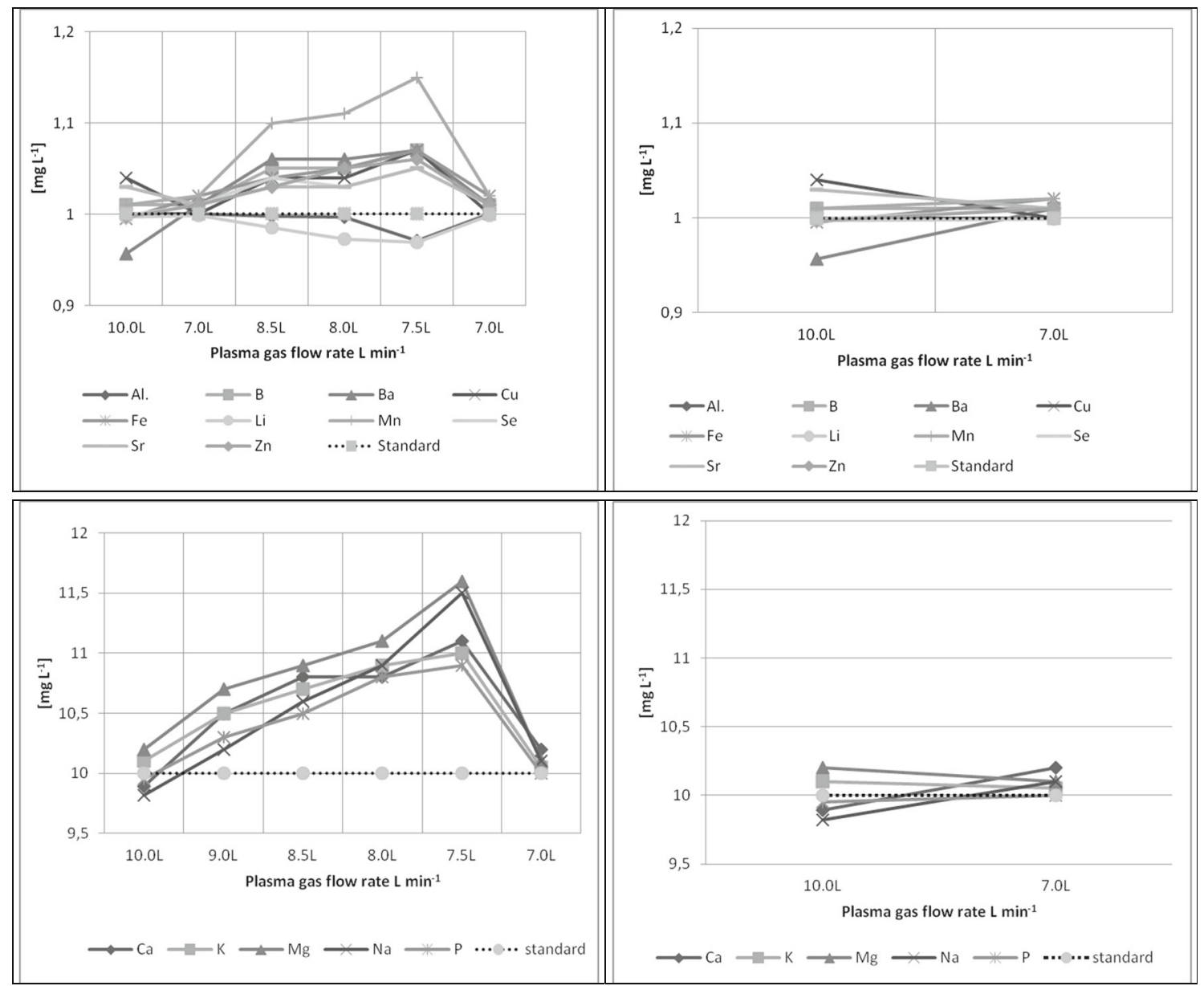

Fig. 1 Influence of the plasma gas flow rate $\left[\mathrm{L} \mathrm{min}^{-1}\right]$ on the concentration of standard solution (1 mg L ${ }^{-1}$ for $\mathrm{Al}, \mathrm{B}, \mathrm{Ba}, \mathrm{Cu}, \mathrm{Fe}, \mathrm{Li}, \mathrm{Mn}, \mathrm{Se}, \mathrm{Sr}, \mathrm{Zn}$ and $10 \mathrm{mg} \mathrm{L}^{-1}$ for $\mathrm{Ca}, \mathrm{Mg}, \mathrm{Na}, \mathrm{P}$, and $\mathrm{K}$ ) 


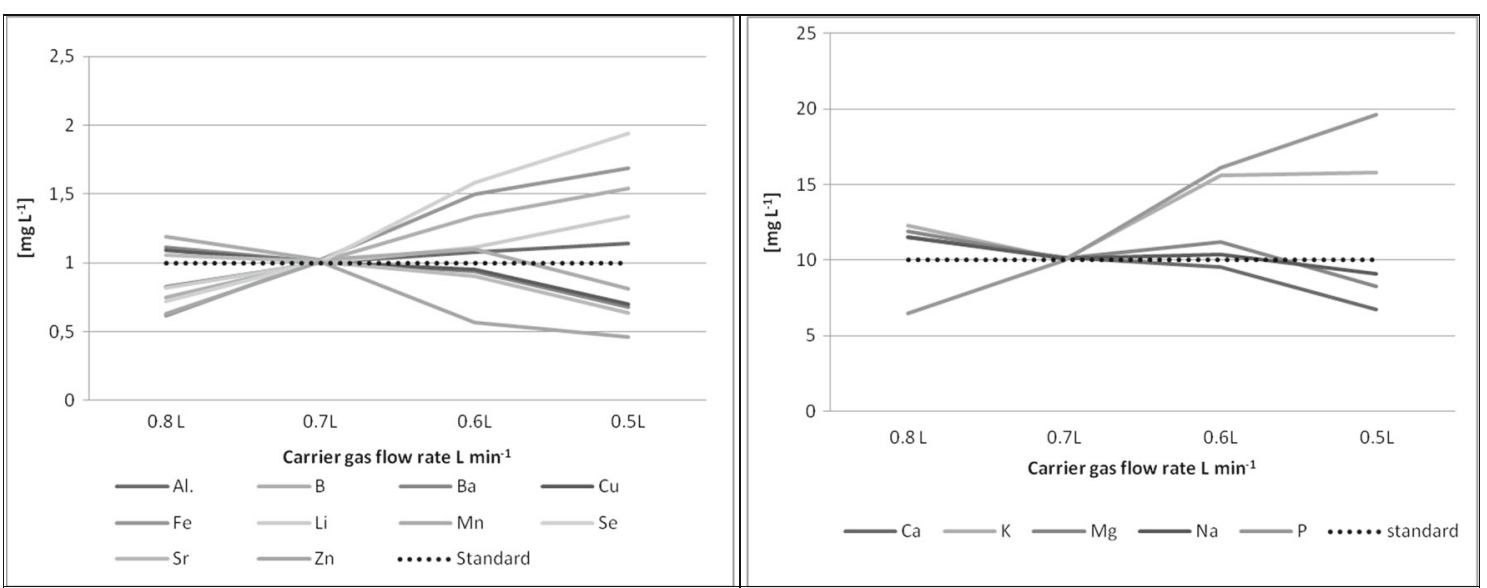

Fig. 2 Influence of carrier (nebulizer) gas flow rate $\left[\mathrm{L} \mathrm{min}^{-1}\right]$ on the concentration of standard solution $\left(1 \mathrm{mg} \mathrm{L}{ }^{-1}\right.$ for $\mathrm{Al}, \mathrm{B}, \mathrm{Ba}, \mathrm{Cu}, \mathrm{Fe}, \mathrm{Li}, \mathrm{Mn}, \mathrm{Se}, \mathrm{Sr}$, $\mathrm{Zn}$ and $10 \mathrm{mg} \mathrm{L}^{-1}$ for $\mathrm{Ca}, \mathrm{Mg}, \mathrm{Na}, \mathrm{P}$ and $\left.\mathrm{K}\right)$. The plasma flow rate is $7.0\left[\mathrm{~L} \mathrm{~min}^{-1}\right]$

components introduced into the ICP plasma. Lower dilution factors significantly hindered determination of trace elements in wine samples. In the case of 1:1, 1:2, and 1:5 $(v / v)$ dilutions, the plasma switched off, which could be associated with too high content of organic compounds and dissolved solids. The similar observation was found in the study of wine analysis by Gonzálvez et al. 2008. The 1:10 dilution enabled the analysis of all 15 investigated elements in wine. The highest concentration of aluminum $\left(1.07 \pm 0.01 \mathrm{mg} \mathrm{L}^{-1}\right)$ was determined in white wine, while in red wines $\mathrm{Al}$ concentration was lower and amounted to $0.6 \mathrm{mg} \mathrm{L}^{-1}$. Boron concentrations were higher in red wines $\left(>5 \mathrm{mg} \mathrm{L}^{-1}\right)$ than in the white one $\left(2.59 \pm 0.02 \mathrm{mg} \mathrm{L}^{-1}\right)$. The concentrations of $\mathrm{Ba}, \mathrm{Cu}, \mathrm{Li}$, and $\mathrm{Se}$ in all wine samples, $\mathrm{Mn}$ in the sample of Roja wine, $\mathrm{Zn}$ in red wines, and $\mathrm{Sr}$ in all wine samples except for Carlo Rossi wine were below $1 \mathrm{mg} \mathrm{L}^{-1}$. The highest concentration of iron was measured in the Roja wine sample $\left(2.02 \pm 0.03 \mathrm{mg} \mathrm{L}^{-1}\right)$ and the lowest in the sample of Resling wine $\left(1.19 \pm 0.07 \mathrm{mg} \mathrm{L}^{-1}\right)$. Manganese ranged from 0.85 to $1.74 \mathrm{mg} \mathrm{L}^{-1}$, and the highest concentration of sodium $\left(7.35 \pm 0.55 \mathrm{mg} \mathrm{L}^{-1}\right)$ was found in the sample of red Carlo
Rossi wine (Fig. 3, Table S1). For $\mathrm{Ca}, \mathrm{Mg}$, $\mathrm{P}$, and $\mathrm{K}$, the concentrations were markedly higher compared to the other elements (Fig. 4, Table S1). As for concentrations of $\mathrm{Ca}, \mathrm{Mg}$, and $\mathrm{P}$, we did not observe any significant differences between particular wine samples. However, potassium concentrations, for which the highest values of all the analyzed elements were determined, were clearly different in the investigated wines.

\section{Microwave-Assisted Digestion}

The wine samples were also pretreated by microwave digestion. The process of digestion destroys organic wine components (ethanol, organic acids, polysaccharides), which leads to reduce their influence on analyte transport efficiency and plasma thermal conditions during analysis by ICP OES technique (Grindlay et al. 2008; Moreno et al. 2008). Similarly as in the case of sample dilution, all the 15 elements were measured in the obtained extracts of wine (Figs. 5 and 6, Table S2). It should be pointed out that concentrations determined for most elements were at the same level as in the case of sample dilution. However, it was observed in all wine samples that the

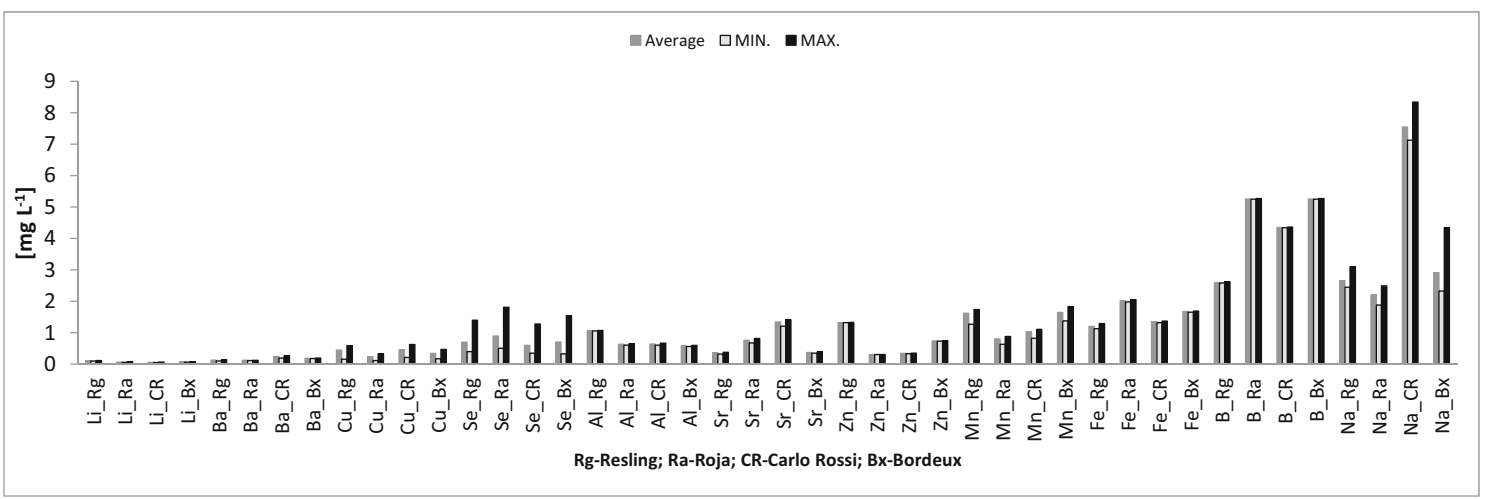

Fig. 3 Results for element concentration in the wine samples (in $\mathrm{mg} \mathrm{L}^{-1}$ ) obtained by ICP OES after dilution 


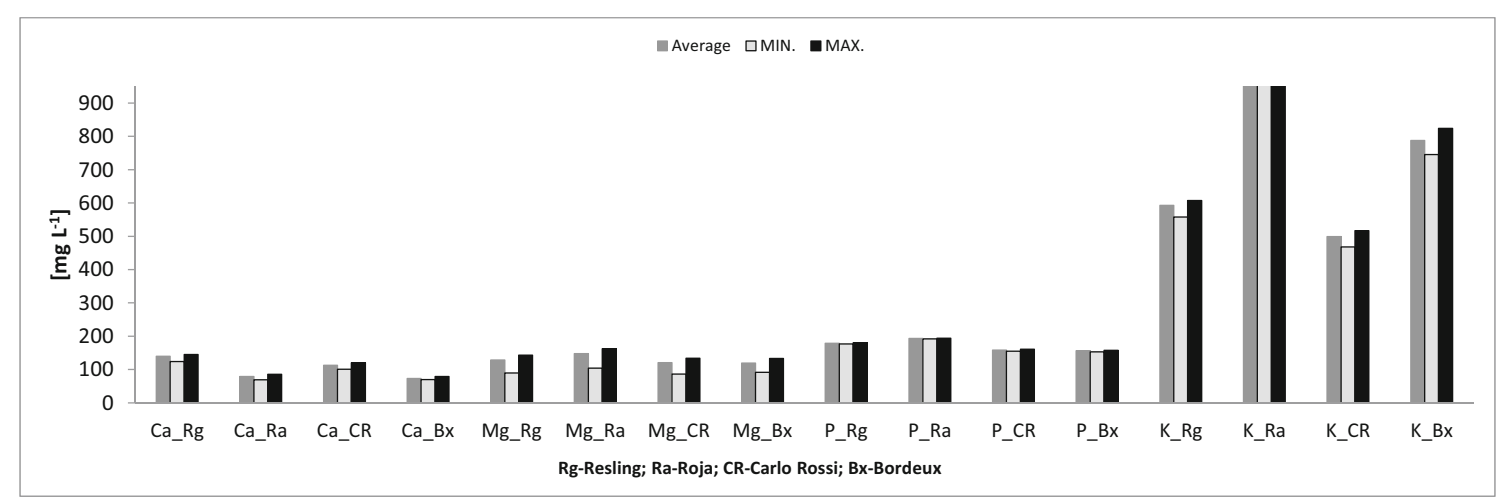

Fig. 4 Results for $\mathrm{Ca}$, Mg, $\mathrm{P}$, and $\mathrm{K}$ concentration (in $\mathrm{mg} \mathrm{L}^{-1}$ ) in the wine samples obtained by ICP OES after dilution

concentrations of aluminum and iron determined in acid extracts were higher and those of selenium and phosphorus were lower. In the cases when twofold higher concentrations of aluminum and iron were found, it was concluded that the acidification of a wine sample could increase the solubility of those metals in wine. In the case of selenium, the obtained concentrations were at least twofold lower than in the sample dilution method. The lower content of Se in digestion samples could be related to oxidation of the metal under the influence of $\mathrm{HNO}_{3}$ and/or could be connected to losses during evaporation depending on the acid composition. This fact was also observed in the determination of Se in the biological materials and cauliflower samples after digestion with acid mixture, containing $\mathrm{HNO}_{3}$ (Somer and Nakisci Ünlü 2006; Somer and Ünal 2004).

\section{Water Bath-Assisted Digestion}

Acid digestion of wine samples was also performed in the open system by using a water bath. The same volumes of wine and acid as in the case of microwave digestion were used. All 15 elements were determined in wine samples (Figs. 7 and 8,
Table S3). Similarly as in the case of microwave digestion, concentrations of aluminum and iron were higher than in the samples pretreated by dilution. It was observed that the concentrations of selenium were lower as compared to the concentrations determined for diluted samples and microwavedigested samples which can be due to analyte losses during the digestion process in the open system similar like in analysis of wine samples by Gonzálvez et al. (2008). The other elements were determined at the same concentration levels as in the samples after microwave digestion.

\section{Comparison of the Efficiency of Sample Pretreatment Methods in Relation to the Results of ICP OES Analysis Under Optimalized Conditions}

Wine samples were prepared using three treatment procedures. The comparison was carried out taking into account all the quantified element results for different analyzed wines, for three combinations of methods on the axes $X$ and $Y$ (Fig. 9). Due to the fact that we obtained different ranges of concentrations for particular elements, the calculations were performed for two sets of results: $<10 \mathrm{mg} \mathrm{L}^{-1}(\mathrm{Al}, \mathrm{B}, \mathrm{Ba}, \mathrm{Cu}$,

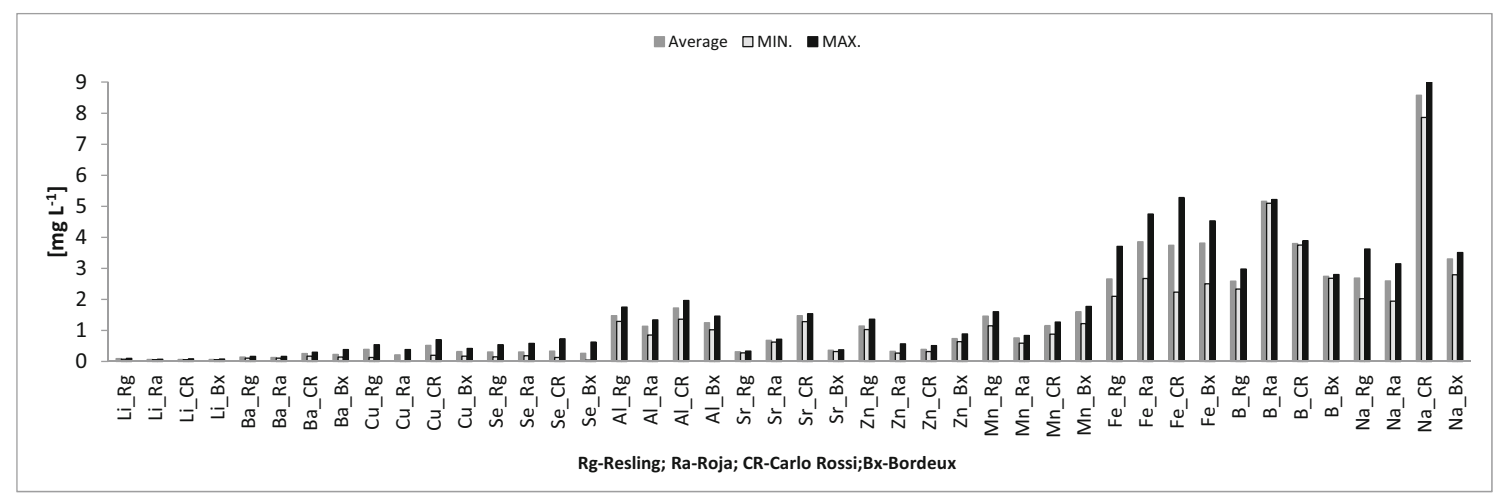

Fig. 5 Results for elements concentration in the wine samples (in $\mathrm{mg} \mathrm{L}^{-1}$ ) obtained by ICP OES after microwave-assisted digestion 


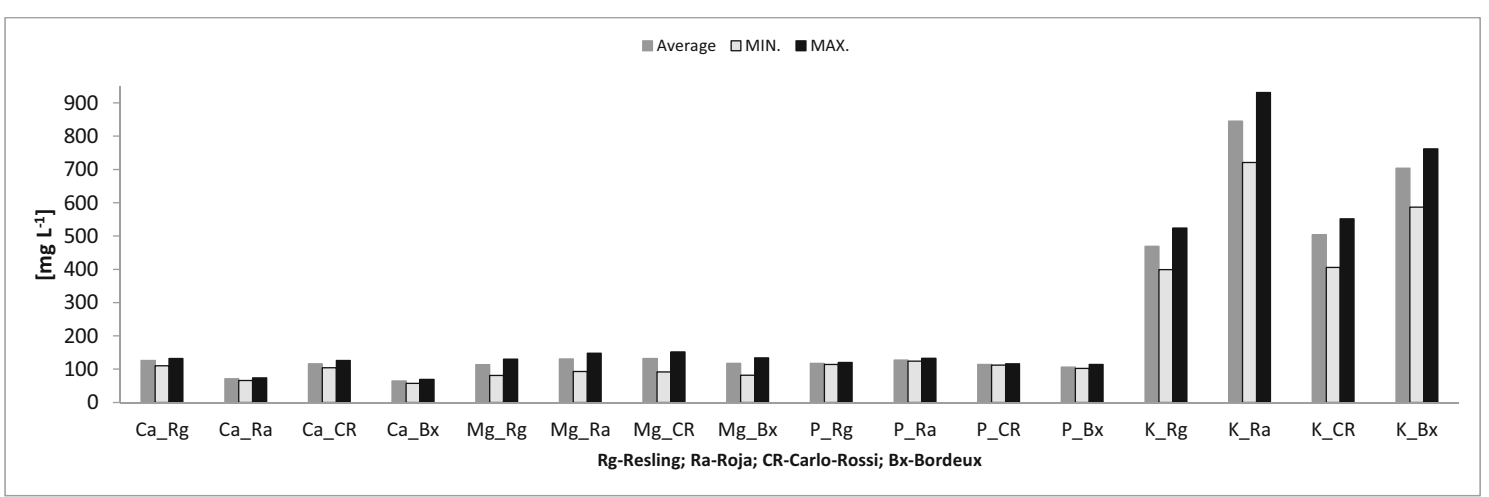

Fig. 6 Results for $\mathrm{Ca}, \mathrm{Mg}, \mathrm{P}$, and $\mathrm{K}$ concentration (in $\mathrm{mg} \mathrm{L}^{-1}$ ) in the wine samples obtained by ICP OES after microwave-assisted digestion

$\mathrm{Fe}, \mathrm{Li}, \mathrm{Mn}, \mathrm{Na}, \mathrm{Se}, \mathrm{Sr}, \mathrm{Zn})$ and $>10 \mathrm{mg} \mathrm{L}^{-1}$ (Ca, Mg, P, K). The determination coefficients for lower $\left(<10 \mathrm{mg} \mathrm{L}^{-1}\right)$ and higher ( $>10 \mathrm{mg} \mathrm{L}^{-1}$ ) concentrations were as follows: (A) $R^{2}=0.838$, (B) $R^{2}=0.840$, (C) $R^{2}=0.997$ and (A) $R^{2}=0.996$, (B) $R^{2}=0.997$, (C) $R^{2}=1.000$, respectively.

The highest $R^{2}$ value was obtained for the case $\mathrm{C}$ (microwave-assisted vs. water bath digestion). The similar determination coefficient $\left(R^{2}=0.997\right)$ was also obtained in the study by Gonzálvez et al. 2008 for elements in wine samples after complete acid digestion in an open vessel ( $Y$-axis) were plotted against those found after microwave-assisted acid digestion $(X$-axis). Moreover, the obtained determination coefficients in our study showed that both digestion methods give comparable results for elements in the lower and higher ranges of concentrations. Therefore, these two methods of sample pretreatment may be used interchangeably. Taking into account the cost of sample preparation, the method of digestion in a water bath is cheaper and more accessible than digestion in a microwave oven.
Based on high determination coefficients for cases A and $\mathrm{B}$, for calcium, magnesium, phosphorus, and potassium, it can be concluded that in order to determine these elements, there is no need for sample digestion with acid and the dilution procedure is enough. It should be highlighted that this founding was not previously obtained by other researchers in analysis of wine samples after dilution or digestion and analyte detection by ICP OES (Gonzálvez et al. 2008; Grindlay et al. 2008). In contrast, $R^{2}$ was $<0.9$ for concentrations $<10 \mathrm{mg} \mathrm{L}^{-1}$ were lower; however, the results were still positively correlated. Based on the obtained results, it was found that the proposed three methods of wine sample preparation give comparable results for the concentration of $\mathrm{B}, \mathrm{Ba}$, $\mathrm{Cu}, \mathrm{Li}, \mathrm{Mn}, \mathrm{Na}, \mathrm{Sr}, \mathrm{Zn}, \mathrm{Ca}, \mathrm{Mg}$, and $\mathrm{K}$ determined by ICP OES. In the case of $\mathrm{Al}$ and $\mathrm{Fe}$ measurements, the obtained results indicated that both methods of sample pretreatment by acid digestion are more efficient than the dilution. For the determination of selenium, it was observed that acid digestion of wine samples can cause losses of Se both in closed and

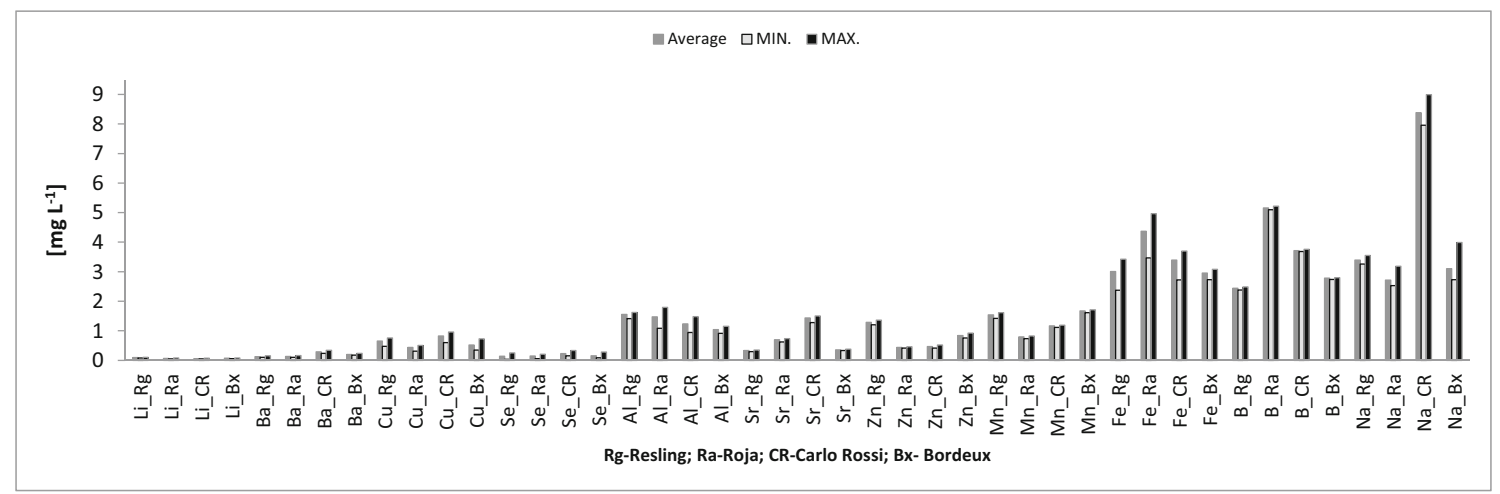

Fig. 7 Results for element concentration in the wine samples (in $\mathrm{mg} \mathrm{L}^{-1}$ ) obtained by ICP OES after water bath-assisted digestion 


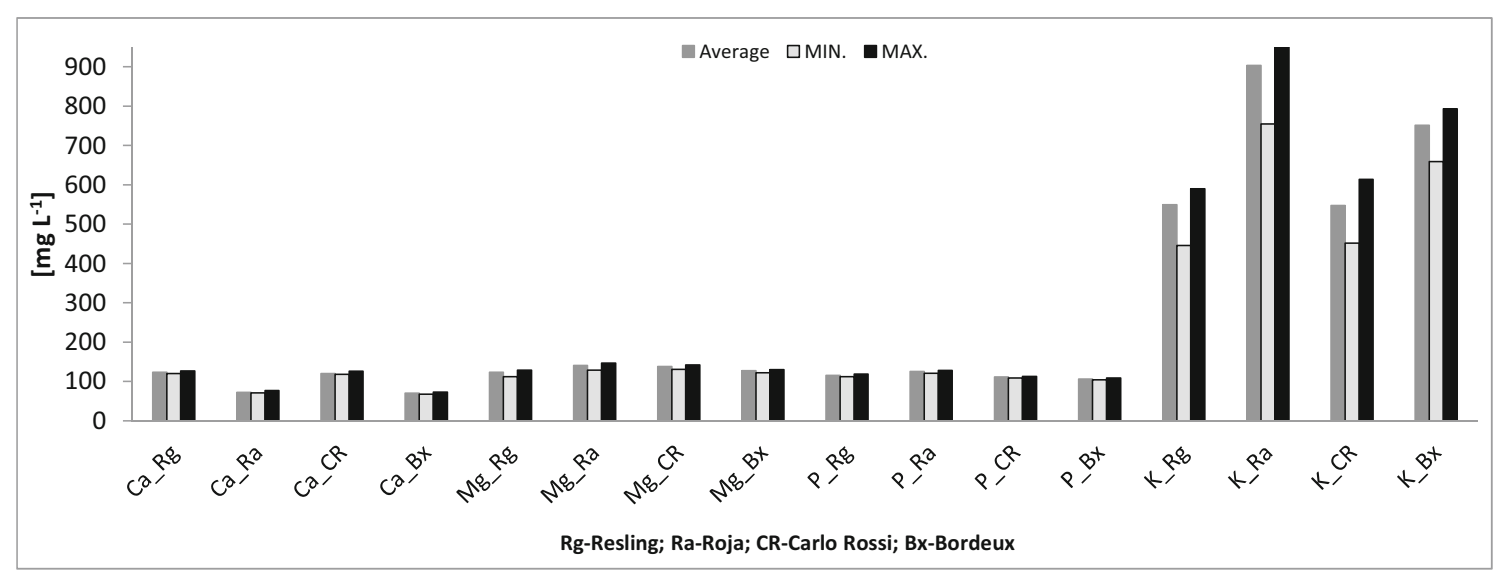

Fig. 8 Results for $\mathrm{Ca}, \mathrm{Mg}, \mathrm{P}$, and $\mathrm{K}$ concentration (in $\mathrm{mg} \mathrm{L}^{-1}$ ) in the wine samples obtained by ICP OES after water bath-assisted digestion

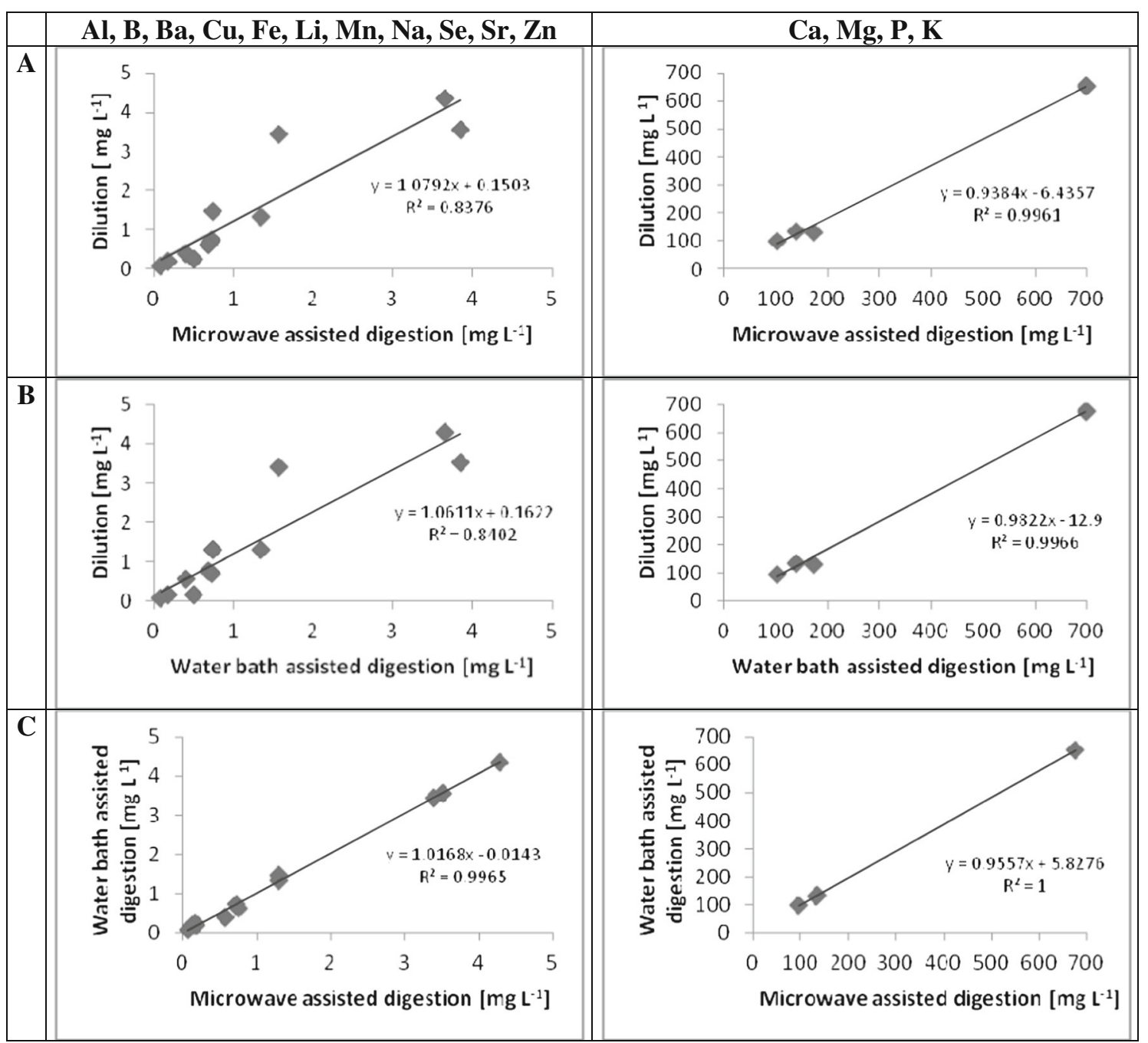

Fig. 9 Results of regression line between average results obtained by ICP OES for the analysis of wines after sample treatment by a dilution (y) plotted against those obtained by microwave-assisted digestion $(x), \mathbf{b}$ dilution $(y)$ plotted against those obtained by water bath-assisted digestion $(x)$, and $\mathbf{c}$ water bath-assisted digestion $(y)$ plotted against those obtained by microwave-assisted digestion $(x)$ 


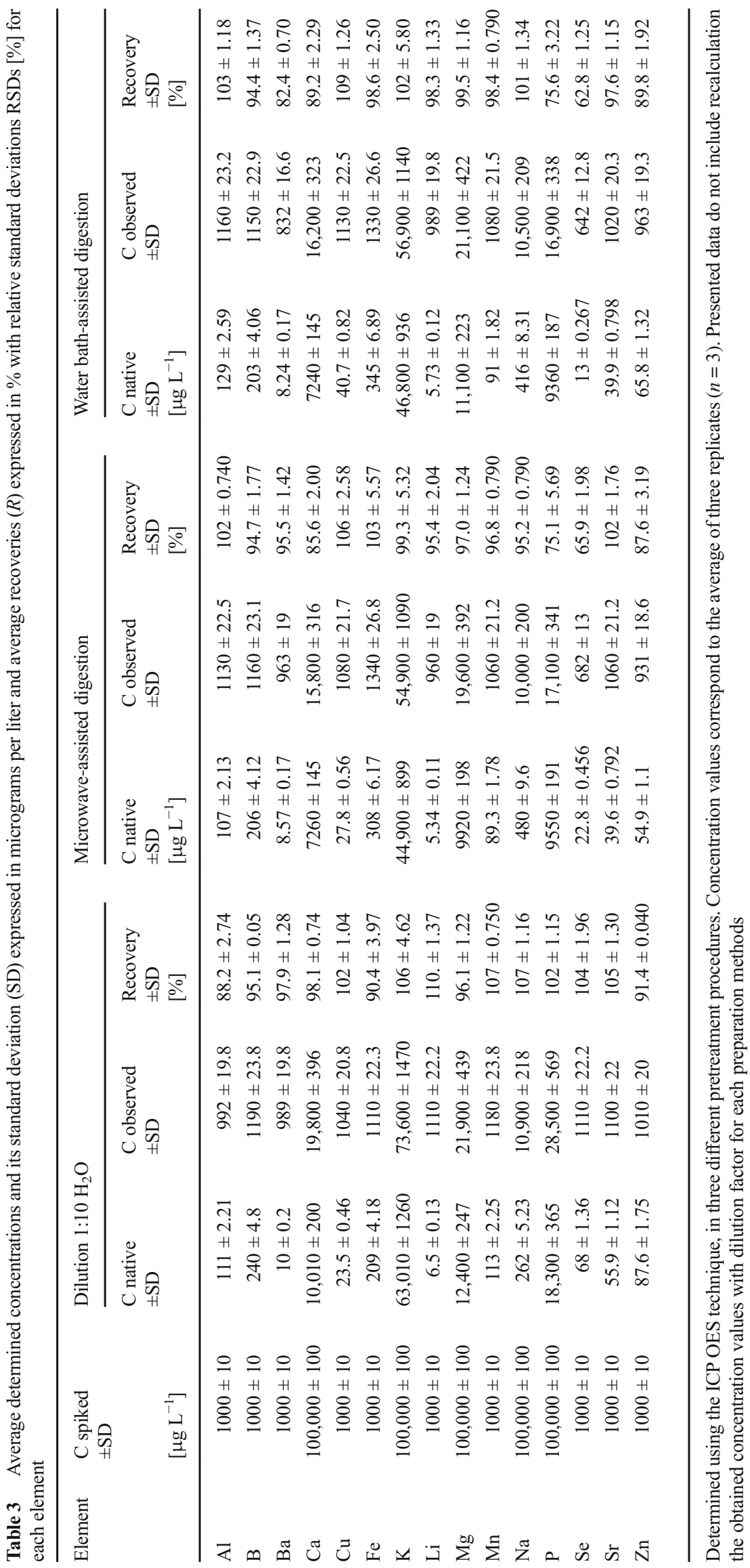


open systems, and because of that, direct measurement of diluted wine is more appropriate method. Also, the dilution method is better for phosphorus determination.

\section{Accuracy}

Commercially available wine reference materials from Chambre d'Agriculture de la Gironde (France 2013) contain certified concentrations of only major elements such as $\mathrm{K}, \mathrm{Ca}$, $\mathrm{Cu}$, and Fe. Also, the Food and Environment Research Agency (USA 2015) developed wine standards with certified concentrations only for $\mathrm{Cd}$ and $\mathrm{Pb}$.

Taking into consideration the complex and unstable nature of wine and due to the lack of multielemental certified wine material, the accuracy of the three sample preparation methods was checked by recovery test. Similar method to evaluate the applied method accuracy in the analysis of wine samples was also used by Grindlay et al. (2008), Grindlay et al. (2014), and Ivanowa-Petropulos et al. (2015), (2016). Also, the recovery test (as a spiking sample with standard solutions) was applied to the determination of metal in tea, wheat, wheat flour, and fruit juice samples using ICP OES technique (Martins et al. 2015; Szymczycha-Madeja and Welna 2013).

In this study, the sample was spiked with the analyte in order to determine a possible proportional bias derived from the sample pretreatment and matrix interference; accuracy was expressed as the recovery of the analyte (Maroto et al. 2001). A solution with known analyte concentration (1 to $10 \mathrm{mg} \mathrm{L}^{-1}$, depending on the actual concentration of elements in a sample) was added to the samples of wine (control sample) prepared in triplicate according to three different procedures. In order to determine the recovery for each method, the following formula was used:

Rij $=\frac{\text { Cobs-Cnative }}{\text { Cspiked }} \times 100$

where Cnative is the analyte concentration in the unspiked control sample, Cobs is the analyte concentration of an element in the spiked sample, and Cspiked is the analyte concentration in the solution added to sample (Maroto et al. 2001; Moreno et al. 2008). The values of recoveries are presented in Table 3. It should be underlined that the presented results obtained concentrations that do not include dilution factor calculation.

It can be observed that the results for sample dilution procedure were the most precise (relative standard deviations (RSDs) $<5 \%$ ). Moreover, for both digestion procedures, the same range of RSDs was determined. The results of recoveries obtained for Se and $\mathrm{P}$ confirmed that acid digestion leads to lower concentrations than the procedure of direct wine sample dilution. In the case of recoveries for $\mathrm{Al}$ and $\mathrm{Fe}$, lower values obtained in the dilution method confirmed that the digestion with acid is a better sample pretreatment method when determination of the investigated elements in wine is intended.

\section{Conclusions}

The use of the mini-torch in a ICP OES spectrometer allowed to reduce the plasma argon flow rate to $7.0 \mathrm{~L} \mathrm{~min}^{-1}$ (standard gas consumption given by the producer- $-10 \mathrm{~L} \mathrm{~min}^{-1}$ ), which significantly lowers the cost of analysis. Three wine sample preparation procedures tested in the present study gave comparable results for most of the 15 determined elements. High determination coefficients $\left(R^{2}\right)$ obtained for both digestion methods indicated that the digestion in the open system in a water bath can be used alternatively with the microwave digestion pretreatment procedure. From the economic point of view, taking into account that high values of recoveries and the lowest RSDs (below $5 \%$ ) were obtained for the simplest pretreatment method, it can be stated that sample dilution can be used as a routine, cheap, and fast procedure for the pretreatment of wine samples.

\section{Compliance with Ethical Standards}

Funding Financial support was provided by the Faculty of Chemistry, Adam Mickiewicz University, in Poznań (Poland).

Conflict of Interest Anetta Zioła-Frankowska declares that she has no conflict of interest. Marcin Frankowski declares that he has no conflict of interest.

Ethical Approval This article does not contain any studies with human or animals performed by any of the authors.

Informed Consent Informed consent was obtained from all individual participants included in the study.

Open Access This article is distributed under the terms of the Creative Commons Attribution 4.0 International License (http:// creativecommons.org/licenses/by/4.0/), which permits unrestricted use, distribution, and reproduction in any medium, provided you give appropriate credit to the original author(s) and the source, provide a link to the Creative Commons license, and indicate if changes were made.

\section{References}

Alkiș TM, Öz S, Atakol A, Yilmaz N, Anli RE, Atakol O (2014) Investigation of heavy metal concentrations in some Turkish wines. J Food Compos Anal 33:105-110

Álvarez M, Moreno IM, Jos AM, Cameán AM, González AG (2007) Study of mineral profile of Montilla-Moriles "fino" wines using inductively coupled plasma atomic emission spectrometry methods. J Food Compos Anal 20:391-395

Chambre d'Agriculture de la Gironde-Service Vigne et Vin, France (2013)www.titrivin@titrivin.com

Gonzálvez A, Armenta S, Pastor A, De La Guardia M (2008) Searching the most appropriate sample pretreatment for the elemental analysis 
of wines by inductively coupled plasma-based techniques. J Agric Food Chem 56:4943-4954

Grindlay G, Mora J, Maestre S, Gras L (2008) Application of a microwavebased desolvation system for multi-elemental analysis of wine by inductively coupled plasma based techniques. Anal Chim Acta 629: 24-37

Grindlay G, Mora J, de Loos-Vollebregt MTC, Vanhaecke F (2014) Evaluation of the multi-element capabilities of collision/ reaction cell inductively coupled plasma-mass spectrometry in wine analysis. Talanta 128:379-385

Ivanowa-Petropulos V, Jakabová S, Nedelkowski D, Pavlík S, Balážová $\mathrm{Z}$, Hegedüs $\mathrm{O}$ (2015) Determination of $\mathrm{Pb}$ and $\mathrm{Cd}$ in Macedonian wines by electrothermal atomic absorption spectrometry (ETAAS). Food Anal Methods 8:1947-1952

Ivanowa-Petropulos V, Balabanova B, Mitrev S, Nedelkovski D, Dimovska V, Gulaboski R (2016) Optimization and validation of a microwave digestion method for multi-element characterization of Vranec wines. Food Anal Methods 9:48-60

Larrera-Marín MT, Pomares-Alfonso MS, Gómez-Juaristi M, SánchezMuniz FJ, Ródenas de la Rocha S (2010) Validation of an ICP-OES method for macro and trace element determination in Laminaria and Porphyra seaweeds from four different countries. J Food Compos Anal 23:814-820

Luis G, Rubio C, Revert C, Espinosa A, González-Weller D, Gutiérrez AJ, Hardisson A (2015) Dietary intake of metals from yogurts analyzed by inductively coupled plasma optical emission spectrometry (ICP-OES). J Food Compos Anal 39:48-54

Maroto A, Boqué R, Riu J, Rius FX (2001) Measurement uncertainty in analytical methods in which trueness is assessed from recovery assays. Anal Chim Acta 440:171-184

Martins CA, Cerveira C, Scheffler GL, Pozebon D (2015) Metal determination in tea, wheat, and wheat flour using diluted nitric acid, highefficiency nebulizer, and axially viewed ICP OES. Food Anal Methods 8:1652-1660

Moreno IM, González-Weller D, Gutierrez V, Marino M, Cameán AM, González AG, Hardisson A (2008) Determination of Al, Ba, Ca, Cu, $\mathrm{Fe}, \mathrm{K}, \mathrm{Mg}, \mathrm{Mn}, \mathrm{Na}, \mathrm{Sr}$ and $\mathrm{Zn}$ in red wine samples by inductively coupled plasma optical emission spectroscopy: evaluation of preliminary sample treatments. Microchem J 88:56-61

Nowak S, Gessel M, Holtkamp M, Scheffer A, Sperling M, Karst U, Buscher W (2014) Low gas flow inductively coupled plasma optical emission spectrometry for the analysis of food samples after microwave digestion. Talanta 129:575-578
Nowak S, Künnemeyer J, Terborg L, Trümpler S, Günsel A, Wiesmüller GA, Karst U, Buscher W (2015) Analysis of whole blood samples with low gas flow inductively coupled plasma-optical emission spectrometry. Anal Bioanal Chem 407:1023-1026

Nunes AM, de Sousa RA, da Silva CS, Peixoto RRA, Vieira MA, Ribeiro AS, Cadore S (2013) Fast determination of Fe, Mg, Mn, P and $\mathrm{Zn}$ in meat samples by inductively coupled plasma optical emission spectrometry after alkaline solubilization. J Food Compos Anal 32:1-5

Péres-Jordán MY, Soldevila J, Salvador A, Pastor A, De La Guardia M (1998) Inductively coupled plasma mass spectrometry analysis of wines. J Anal At Spectrom 13:33-39

Pyrzyńska K (2007) Chemical speciation and fractionation of metals in wine. Chem Speciat Bioavailab 19(1):1-8

Rodrigues SM, Otero M, Alves AA, Coimbra J, Coimbra MA, Pereira E, Duarte AC (2011) Elemental analysis for categorization of wines and authentication of their certified brand of origin. J Food Compos Anal 24:548-562

Santos DCMB, Carvalho LSB, Lima DC, Leão DJ, Teixeira LSG, Korn MGA (2014) Determination of micronutrient minerals in coconut milk by ICP OES after ultrasound-assisted extraction procedure. J Food Compos Anal 34:75-80

Somer G, Nakisci Ünlü A (2006) The effect of acid digestion on the recoveries of trace elements: recommended policies for the elimination of losses. Turk J Chem 30:745-753

Somer G, Ünal Ü (2004) A new and direct method for the trace element determination in cauliflower by differential pulse polarography. Talanta 62(2):323-328

Szymczycha-Madeja A, Welna M (2013) Evaluation of a simple and fast method for the multi-elemental analysis in commercial fruit juice samples using atomic emission spectrometry. Food Chem 141: 3466-3472

The Food and Environment Research Agency, UK (2015) www.fapas.com

Thiel G, Danzer K (1997) Direct analysis of mineral components in wine by inductively coupled plasma optical emission spectrometry (ICPOES). Fresenius J Anal Chem 357:553-557

Voica C, Dehelean A, Pamula A (2009) Method validation for determination of heavy metals in wine and slightly alcoholic beverages by ICP-MS. J Phys Conf Ser 182:1-5

Yabuta H, Miyahara H, Watanabe M, Hotta E, Okino A (2002) Design and evaluation of dual inlet ICP torch for low gas consumption. J Anal At Spectrom 17:1090-1095 